\title{
In vitro effect of toluene diisocyanate on beta adrenergic and muscarinic receptor function in lung tissue of the rat
}

\author{
P J A BORM, ${ }^{1}$ A BAST, ${ }^{2}$ O P ZUIDERVELD ${ }^{2}$ \\ From the Department of Occupational Medicine, ${ }^{1}$ State University of Maastricht, 6200 MD Maastricht, and \\ Department of Pharmacochemistry, ${ }^{2}$ Faculty of Chemistry, Free University, 1081 HV Amsterdam, The \\ Netherlands
}

ABSTRACT To investigate the role of pharmacological mechanisms in toluene diisocyanate (TD induced occupational asthma, the effects of TDI on rat trachea ring and lung parenchymal strip wers studied in vitro. The most prominent effect observed was a stimulation of metacholine $(1 \mu \mathrm{M})$ induced contraction of the tracheal ring by $1 \mu \mathrm{M}$ TDI (added in dimethy sulphoxide). The results were less pronounced when TDI was added from a stock solution prepared in water, which is possibly due (co)polymerisation. It is concluded that the pharmacological effect of TDI may result from ant autonomic imbalance between cholinergic and B-adrenergic neural control.

Toluene diisocyanate (TDI), a highly reactive chemical used as a polymerising agent in the production of polyurethane foams, plastics, and adhesives, is known to cause bronchial asthma in some of those exposed to it. ${ }^{1-3}$

Immediate, late, and dual type asthma may develop even in response to low concentrations of TDI (less than $0.001 \mathrm{ppm}){ }^{4}$ Asthma is believed to develop in about $5 \%$ of workers regularly exposed to TDI, and most have been non-atopic. ${ }^{\text {s }}$ The underlying cause of isocyanate asthma is not understood, although immunological and pharmacological mechanisms have been proposed. ${ }^{6-10}$

Without questioning the immunological mechanisms involved we were puzzled with the contradictory pharmacological in vivo and in vitro data. The early observation that almost half of TDI bronchoprovocation positive patients failed to show manifestations of histamine hyperreactivity ${ }^{4}$ led Bernstein to the suggestion that "under appropriate conditions that cannot be defined precisely at the present time, diisocyanate compounds may act as direct pharmacological agonists or as inducers of non-specific bronchial hyperreactivity." 10

The idea that neural control may be abnormal in asthma ${ }^{11}$ generated the design of the present investigation: elucidating the effect of TDI on muscarinic and beta-adrenergic receptor function using two different experimental systems: isolated rat trachea ring and the

Accepted 4 January 1988 lung parenchymal strip. We used the laryngeal portio of the trachea which is well innervated and the lung parenchymal strip which is poorly innervated.

\section{Material and methods}

CHEMICALS

TDI was purchased from Merck (art No 808264) an⿳⺈, was a mixture of $2,4-$ TDI $(80 \%)$ and $2,6-$ TDI $(20 \%$ (-) isoprenaline hydrochloride and metacholin $\vec{E}$ chloride were products of Sigma Chemical Co, $\mathbf{S}$ Louis, Mo, USA. All other reagents used were of reagent grade.

\section{METHODS}

Male Wistar rats (240-330 g, TNO Zeist, The Netloerlands) were killed by a blow on the head and ble The organs were rapidly excised and after preparation mounted in a water jacketed organ bath at a tem perature of $37^{\circ} \mathrm{C}$. The bath contained Krebs buffer $\left(\mathrm{NaCl} 117.5 \mathrm{mM}, \mathrm{KCl} 5.6 \mathrm{mM}, \mathrm{MgSO}_{4} 1.18 \mathrm{mM}^{2}\right.$ $\mathrm{CaCl}_{2} 2.5 \mathrm{mM}, \quad \mathrm{NaH}_{2} \mathrm{PO}_{4} 1.28 \mathrm{mM}, \mathrm{NaHCO}$ $25.0 \mathrm{mM}$, and glucose $5.5 \mathrm{mM}$ ) which was gassed wit⿱ a mixture of $95 \% \mathrm{O}_{2}$ and $5 \% \mathrm{CO}_{2}$ to maintain oxyge tension and a pH of $7 \cdot 4$.

The TDI used in all experiments was prepared fresh before the start of each experiment and dilutions were made in water or in dimethyl sulphoxide (DMSO). 侮 the latter case control experiments were performeg with an equal amount of DMSO that did not exceed final concentration of $1 \%$ DMSO (v/v) in the organ bath. 


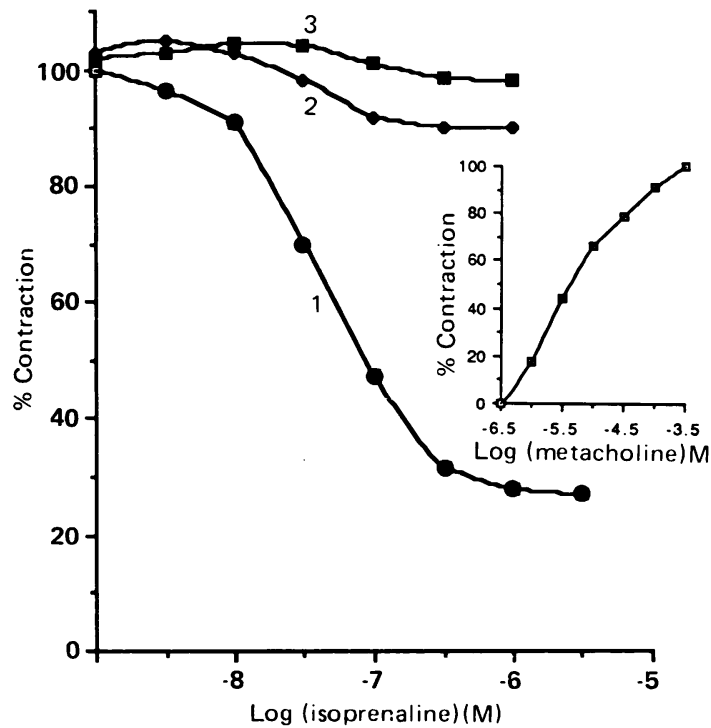

Fig 1 Concentration dependent relaxation by (-)isoprenaline on trachea preparation of rat after contraction by $10^{-6} \mathrm{M}(1), 3 \cdot 10^{-6} \mathrm{M}(2)$, and $10^{-5} \mathrm{M}$ (3) metacholine. Precontraction by metacholine has been depicted as $100 \%$. Insert: Cumulative dose response curve of metacholine. All curves are mean of at least three separate experiments.

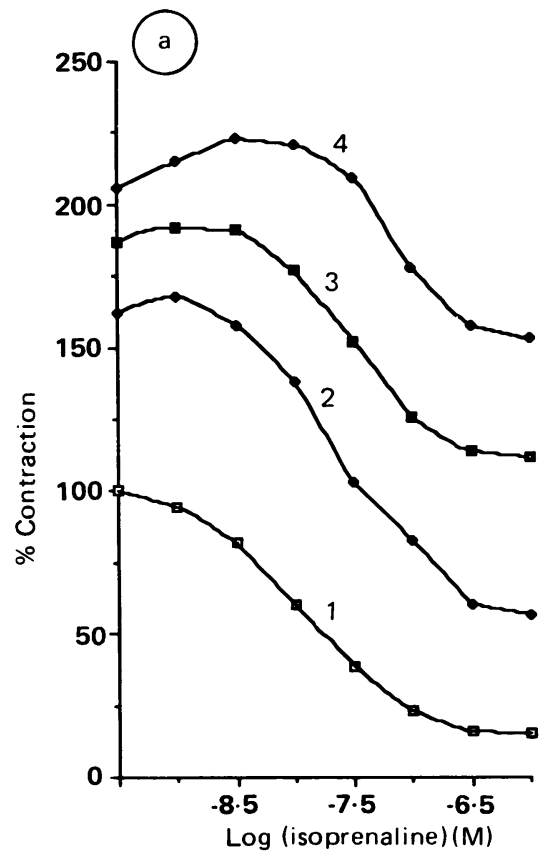

Single trachea rings cut at the site opposite to the muscles were used. A passive force of $0.4 \mathrm{~g}$ was applied and recording was performed isotonically using a Hugo Sachs TL-2 Hebelaufnehmer. After an equilibrium period of 40 minutes with four intermediary washings either a cumulative dose response curve of metacholine or a cumulative dose response curve (-)isoprenaline (after precontraction for 15 minutes with metacholine at a concentration indicated) was recorded. At the start of each experiment two dose response curves with (-)isoprenaline were obtained, the second serving as a control. Between each curve two rapid washings with a subsequent washing period of 30 minutes with three intermediate washings was applied. After the second curve the trachea preparation was incubated with TDI for 30 minutes; subsequently the metacholine precontraction was induced (15 $\mathrm{min})$ and a cumulative dose response curve for isoprenaline was recorded.

Parenchymal strips (isotonically recorded, with a passive force of $0.4 \mathrm{~g}$ ) were equilibrated for $\mathbf{4 0}$ minutes in Krebs buffer as described above, during which four intermediate washings were performed. Cumulative dose response curves were obtained as described for the tracheal ring according to Kramer et al..$^{12}$

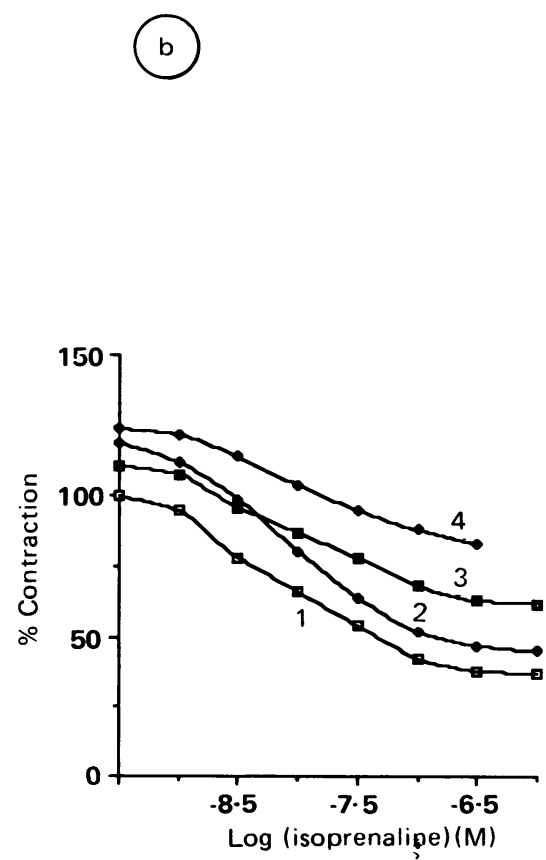

Fig $2 \mathrm{a}$ and $\mathrm{b}$ Effect of TDI (dissolved in DMSO) on precontraction induced by metacholine $\left(10^{-6} \mathrm{M}\right)$ and subsequent isoprenaline concentration dependent relaxation at TDI concentrations of 0 (1), $10^{-6} M(2), 10^{-5} M(3)$, and $10^{-4} M(4)$. Figure $2 b$ as in $2 a$, except that TDI was dissolved in water just before administration to organ bath. All curves are mean of at least two separate experiments. 


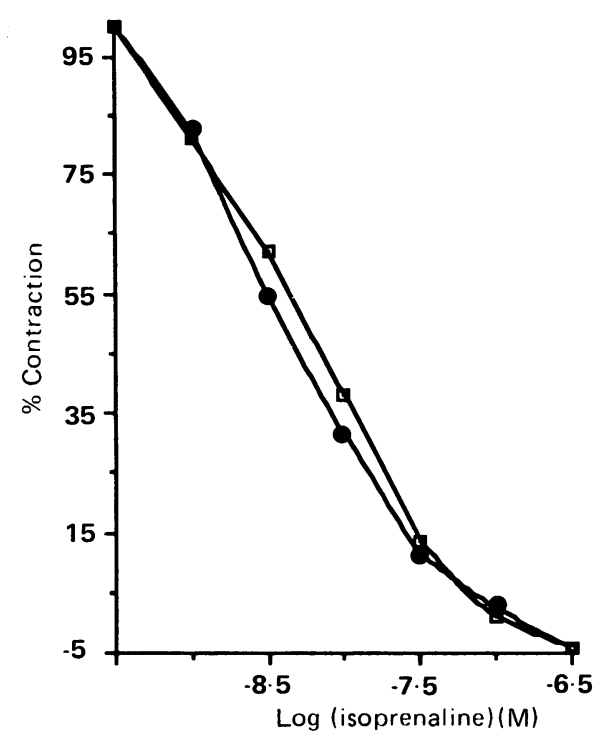

Fig 3 Absence of any effect of TDI $\left(10^{-4} \mathrm{M}\right.$ dissolved in DMSO) on precontraction of trachea ring induced by $10^{-6} \mathrm{M}$ metacholine and subsequent isoprenaline line concentration dependent relaxation. - indicates control experiment (DMSO only) and $\square$ indicates relaxation in presence of $10^{-4} \mathrm{M}$ TDI. Curves are mean of at least two separate experiments.

Results

TRACHEAL SMOOTH MUSCLE

To obtain a maximal relaxation effect in isolated trachea ring, we established the effect of precontraction on maximal relaxation. Precontraction was tuned by varying metacholine concentrations (fig 1). The insert in fig 1 shows the concentration response relation for metacholine. From fig 1 it is clear that when increasing the precontraction of the trachea ring, the pD2 value (logarithm of the isoprenaline concentration that produces a half maximal relaxation) decreases, whereas the maximal relaxation also decreases.

Figure 2 shows the effect of preincubation and presence of various concentrations of TDI added in DMSO (fig 2a) or in water (fig 2b) on the relaxation curves induced by isoprenaline in the tracheal preparation. Firstly, we observed a dose dependent activation of the muscarinic response to $1 \mu \mathrm{M}$ metacholine. Moreover, TDI has an effect on the maximal relaxation induced by the addition of isoprenaline (fig 2a). A gradual decrease of the maximal relaxation attainable with isoprenaline is observed when the TDI concentration is increased. The maximal relaxation at $10^{-4} \mathrm{M}$ TDI is about $62 \%$ of the control value.

The same qualitative effects were observed when adding TDI in aqueous solution without DMSO,

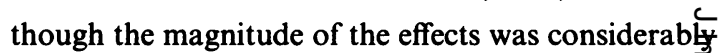
smaller (fig 2b).

\section{LUNG PARENCHYMA STRIP}

Experiments using the isolated lung strip failed show any effect of TDI $\left(10^{-6} \mathrm{M}, 10^{-5} \mathrm{M}, 10^{-4} \mathrm{M}\right)$ on the half maximal contracted strip (contraction induced bi $1 \mu \mathrm{M}$ metacholine), nor was any effect detected of TD on the isoprenaline induced relaxation of the stri brought into contraction with $1 \mu \mathrm{M}$ metacholine (fig 3). In both experiments final concentrations of TDI in DMSO/water up to $0.1 \mathrm{mM}$ were tested Because no effects were observed only the latter concentration is shown in fig 3 .

\section{Discussion}

Beta adrenergic blockade has been proposed as on mechanism by which TDI induced asthmatic reactiong may be explained..$^{713} \mathrm{~A}$ major reason to suppose thæ this is the case was the finding that TDI suppressed the stimulation of lymphocyte cAMP levels by the $\beta^{*}$ agonist isoprenaline. Moreover, McKay and Brooks using frog erythrocytes, showed that direct stimula

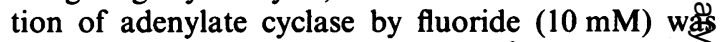
significantly reduced by TDI $(1 \mathrm{mM}){ }^{9}$ These findings suggest that impairment of the $\beta$-adrenergic respons may play an important part in TDI induced bo choconstrictive effects. Several studies have shew that all individuals who react to TDI are highis metacholine sensitive. ${ }^{814}$

The results of this study clearly show that TLO enhances the muscarinic response to metacholine the trachea of the rat in vitro (fig 2). The sanfe concentrations of TDI, however, fail to produce a effect on the metacholine response in the lung pare chymal strip (fig 3 ). The difference between the effect of TDI dissolved in DMSO or water might explained by (co)polymerisation of TDI in water (fig $2 \mathrm{a}, 2 \mathrm{~b})$ thereby leading to a decrease in the reactize concentration in the tissue. As a result, TDI dissolved in water causes effects similar to those provoked byga TDI/DMSO solution, but the extent of the response $\$$ less pronounced.

The activation of the response to metacholine in ou study could be explained by the inhibitory action TDI on acetylcholinesterase as reported..$^{1516}$ In add tion, owing to the chemically reactive properties TDI, a wide variety of other functionally important components mediating methacholine response may 48 affected. Irrespective of the ultimate cause of the increased metacholine responsiveness, it implies that relaxation by any $\beta$-adrenergic agonist demands higher equiactive concentration of the agonist. In figg it is shown that isoprenaline relaxes the rat trachea strip preparation previously precontracted by metse 
choline and that the potency of isoprenaline as a spasmolytic is inversly proportional to the strength of the contraction (achieved by varying concentrations of metacholine). Such a phenomenon (functional antagonism) results from the assumption that a higher receptor occupancy with isoprenaline is needed at higher metacholine concentrations to obtain the same effect (for detailed theoretical discussion see Kenakin $^{17}$ ).

In addition to a change in equiactive concentration of isoprenaline at different muscle tone, the maximal attainable relaxation is also altered by the tone applied. At an increasing muscle tone the magnitude of maximal relaxation decreases (fig 1 and Kenakin ${ }^{17}$ ).

TDI had no effect on metacholine or isoprenaline induced responses in lung parenchymal tissue. The conditions used to tune the tracheal rings precontraction $(0.4 \mathrm{~g}$ passive force and precontraction with $1 \mu \mathrm{M}$ metacholine) cause a $20 \%$ maximal contaction in this preparation. Identical experimental conditions resulted in a $50 \%$ of maximal contraction (data not shown) in the parenchymal strip.

These findings support the view that the tone applied to "contract" the preparation determines the quantitative effect of the modulator. Moreover, one should also be aware that a passive force of $0.4 \mathrm{~g}$ does not imply the same intrinsic tone in both preparations.

The decrease caused by TDI in relaxation induced by isoprenaline might be explained by a direct effect of TDI on the $\beta$-receptor response; in addition, the increase of the contraction caused by TDI immediately implies an apparently decreased isoprenaline potency.

In conclusion, the pharmacological effect of TDI in lung tissue may result from an autonomic imbalance. This mainly holds for the innervated portion of the lungs, the large airways. We hypothesise that neural control becomes abnormal when TDI is administered because the balance is tipped in favour of bronchoconstrictor mechanisms (increase in metacholine response) and away from bronchodilator mechanisms (diminished $\beta$-adrenergic effects-direct and indirect).

We are greatly indebted to B de Rooy and A Civil for their technical help and to Marliese van Wissen for carefully preparing the manuscript.
Requests for reprints to: Dr P J A Borm, Department of Occupational Medicine, State University of Maastricht, PO Box 616, 6200 MD Maastricht.

\section{References}

1 Parkes WR. Occupational asthma (including byssinosis). In: Parkes WR, ed. Occupational lung disorders. London: Butterworths, 1982:415-52.

2 Cockcroft DW, Mink JT. Isocyanate-induced asthma in an automobile spray painter. CMA Journal 1979;121:602-4.

3 White WG, Sugden E, Morris MJ, Zapata E. Isocyanate-induced asthma in a car factory. Lancet 1980;ii:756-60.

4 O'Brien IM, Newman Taylor AJ, Burge PS, Harries MG, Fawcett IW, Pepys J. Toluene diisocyanate-induced asthma. II. Inhalation challenge tests and bronchial reactivity studies. Clin Allergy 1979;9:7-11.

5 Venables KM. Epidemiology and the prevention of occupational asthma. Br J Ind Med 1987;44:73-5.

6 Butcher BT, Salvaggio JE, Weill H, Ziskind MM. Toluene diisocyanate (TDI) pulmonary disease: immunologic and inhalation challenge studies. $J$ Allergy Clin Immunol 1976;58:89-100.

7 Butcher BT, Salvagio JE, O'Neil CE, Weill H, Garg O. Toluene diisocyanate pulmonary disease: immunopharmacologic and mecholyl challenge studies. J Allergy Clin Immunol 1977; 59:223-7.

8 Butcher BT, Karr RM, O'Neil CE, et al. Inhalation challenge and pharmacologic studies of toluene diisocyanate (TDI)-sensitive workers. J Allergy Clin Immunol 1979;64:146-52.

9 McKay RT, Brooks SM. Effect of toluene diisocyanate on beta adrenergic receptor function. Am Rev Respir Dis 1983;128:50-3.

10 Bernstein IL. Isocyanate-induced pulmonary diseases: a current perspective. J Allergy Clin Immunol 1982;70:24-31.

11 Barnes PJ. Neural control of human airways and disease. Am Rev Respir Dis 1986;134:1289-1314.

12 Kramer K, Doelman CJA, Timmerman H, Bast A. A disbalance between beta-adrenergic and muscarinic responses caused by hydrogen peroxide in rat airways in vitro. Biochem Biophys Res Commun 1987;145:357-62.

13 Van Ert M, Battigelli MC. Mechanism of respiratory injury by TDI (toluene diisocyanate). Ann Allergy 1975;35:142-7.

14 Mapp CE, Di Giacomo GR, Omini C, Broseghini C, Fabbri LM. Late, but not early, asthmatic reactions induced by toluenediisocyanate are associated with increased airway responsiveness to metacholine. Eur J Resp Dis 1986;69:276-84.

15 Brown WE, Green AH, Karol MH, Alarie YCE. Inhibition of cholinesterase activity by isocyanates. Toxicol Appl Pharmacol 1982;63:45-52.

16 Dewair M, Baur X, Mauermayer R. Inhibition of acetylcholinesterase by diisocyanates and its spontaneous reactivation. Int Arch Occup Environ Health 1983;52:257-61.

17 Kenakin TP. The quantification of relative efficacy of agonists. Journal of Pharmacological Methods 1985;13:281-308. 